\title{
Frameless Stereotactic Radiosurgery With Linear Accelerator (LINAC)-Based Technology for Brain Metastases: Outcomes Analysis in 141 Patients
} Aisin Ibrahim ${ }^{1}$, Bernard Fortin ${ }^{2}$, Alexis Bujold ${ }^{2}$, Nader Kaouam ${ }^{2}$, Alma Sylvestre ${ }^{2}$, Christian Boukaram ${ }^{2}$

1. Department of Diagnostic Radiology, McGill University, Montréal, CAN 2. Department of Radiation Oncology, Maisonneuve-Rosemont Hospital, Université de Montréal, Montréal, CAN

Corresponding author: Aisin Ibrahim, aisin.ibrahim.med@ssss.gouv.qc.ca

\section{Abstract \\ Objectives}

Brain metastases (BM) are the most common intracranial tumors in adults. Surgery and frame-based stereotactic radiosurgery (SRS) are well-described treatment options. Frameless SRS is an emerging BM treatment option offering fewer side effects. The aim of this study was to describe the therapeutic outcomes and toxicity of frameless SRS with linear accelerator (LINAC)-based technology for BM treatment in our institution.

\section{Materials and methods}

We performed a retrospective study including all adult patients treated with frameless SRS with LINACbased technology for BM between October 2010 and July 2016. Patients were followed routinely with MRI scans at three-month intervals. Primary endpoints were progression-free survival, local control, overall survival, and toxicity related to the treatment. All survival times were computed with the Kaplan-Meier method. All cumulative incidences were computed using competing risk analyses.

\section{Results}

A total of 194 metastatic lesions in 141 patients were treated in a 69-month interval. At the time of analysis, 33 patients were still alive, with a median follow-up time of 25.1 months. The overall median survival was 8.7 months. The median progression-free survival was 5.3 months. Local recurrence as a first event was $25 \%$ and $38 \%$ at one and two years, respectively, while distant brain recurrence as a first event was $18 \%$ and $21 \%$. Death before any brain event occurred in $31 \%$ of patients. The cumulative incidence of radiation necrosis as a first brain event was $2 \%$ at one and two years.

\section{Conclusions}

Review began 05/07/2021 Review ended 05/29/2021 Published 06/06/2021

\section{๑) Copyright 2021}

Ibrahim et al. This is an open access article distributed under the terms of the Creative Commons Attribution License CC-BY 4.0., which permits unrestricted use, distribution, and reproduction in any medium, provided the original author and source are credited.
The treatment of BM with LINAC-based frameless SRS in our institution had an overall and progression-free survival comparable with the literature for frameless SRS and for conventional frame-based SRS while being less invasive and more comfortable for the patient. In our study, frameless SRS with LINAC technology seems to be safe for BM treatment with minimal rates of radiation necrosis.

Categories: Radiation Oncology, Oncology

Keywords: linac based srs, frameless stereotactic radiosurgery, radionecrosis, brain stereotactic radiosurgery, brain metastasis, treatment of brain metastases

\section{Introduction}

Brain metastases (BM) are the most common intracranial tumors in adults. Between $20 \%$ and $40 \%$ of cancer patients develop BM for which a variety of therapeutic options are available, including surgery and radiotherapy [1]. Stereotactic radiosurgery (SRS) has been established as a favorable option in the management of BM [1]. SRS can be used with or without prior surgical resection (Sx) or whole-brain radiation therapy (WBRT) [1-2].

SRS is a high-precision technique that delivers a significant dose of radiation to a localized volume of an organ while minimizing radiation to healthy tissue surrounding it [3]. Conventional radiosurgery was first described in the form of Gamma Knife ${ }^{\circledR}$ (Elekta, Stockholm, Sweden) by Dr. Lars Leksell in 1951. This technique required the use of a rigid head frame for the immobilization of the patient in order to target a precise location in the brain [4]. Although this invasive system provides a high degree of accuracy, it is associated with multiple disadvantages for the patient like pain and anxiety. Also, the rigid head frame requires the presence of a neurosurgeon for frame installation [5-6]. 
There is now a variety of frameless SRS systems using linear particle accelerator (LINAC) technology that do not require a surgical rigid frame installation while providing better conformity to odd-shaped lesions and sparing of eloquent regions [7]. The aim of this study was to document the therapeutic outcomes and toxicity of frameless SRS with LINAC-based technology for BM in our institution and compare our results with the literature on BM treatment.

\section{Materials And Methods}

\section{Patient selection}

This is a retrospective study performed at Maisonneuve-Rosemont Hospital between October 2010 and July 2016. We included all adult patients who underwent frameless SRS for BM with good Recursive Partitioning Analysis (RPA) and Graded Prognostic Assessment (GPA) scores [8-9]. Other inclusion criteria were oligometastatic brain disease ( $<5$ metastasis), BM largest diameter $<4 \mathrm{~cm}$, documented primary cancer with a pathology report, controlled extra-cranial disease, and a good Karnofsky performance status (KPS). Patients were assessed by a multidisciplinary team including neurosurgeons, oncologists, and radiation oncologists.

\section{Non-invasive SRS system and procedures}

Patients were immobilized with a frameless system using an individualized mask molded with a thermoplastic pellet a few days prior to the intervention. A personalized intra-oral thermoplastic piece was incorporated to provide additional rigidity. The time required to produce these masks was between 30 and 45 minutes. The patient immobilization technique and mask molding is shown in Figures $1 \mathrm{~A}-1 \mathrm{C}$.

A),

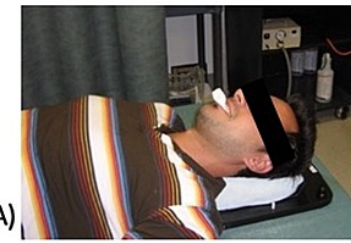

B)

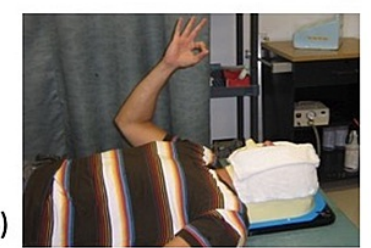

C)

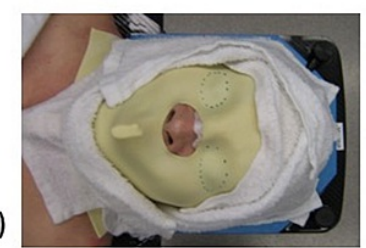

\section{FIGURE 1: Patient immobilization and frameless SRS mask molding technique}

(A) A mouthpiece of thermoplastic aquaplast $5 \mathrm{~mm}$ is softened and molded to the patient's mouth by slightly biting with his incisors. (B) Molding of the mask with the mouthpiece in place. (C) Mask left cooling on the patient for about 15 minutes, drawing of the eyes' limits on the mask, which are later cut out.

SRS: stereotactic radiosurgery

Following the mask molding, a computed tomography scan (CT) of the brain with contrast was performed with a reconstructed slice thickness of 1 to $1.5 \mathrm{~mm}$. The images were then fused with recently performed gadolinium-enhanced magnetic resonance imaging (MRI) of the brain. Then, contouring of the lesion was done by a radiation oncologist and a margin of 1 to $3 \mathrm{~mm}$ was added to the gross tumor volume (GTV) to obtain the planning targeted volume (PTV). The contour of the target lesions and the organs at risk were reverified by a second radiation oncologist before beginning dosimetry planning.

An Elekta Synergy-S ${ }^{\circledR}$ system was used. The patient's positioning was verified with an on-board cone-beam CT. A HexaPOD ${ }^{\mathrm{TM}}$ (Elekta) table was also used for corrections. This allows for repositioning in all axes including rotations.

Patients were candidates to either receive a single dose of radiation or fractionated radiotherapy. The prescribed dose to the PTV was between 12 and 24 Gy with a 15 Gy median. The final radiation dose was decided according to the location and the tumor's largest diameter [10-12]. Moreover, the volume of tissue receiving more than $10 \mathrm{~Gy}$ (V10) or $12 \mathrm{~Gy}$ (V12) was taken into consideration in the final radiation dose, as it is an important predictor of radionecrosis (RN) according to Blonigen et al. [13].

\section{Follow-up and statistical analysis}

After radiation treatments, the patients were followed routinely with brain MRI at three-month intervals or as clinically indicated. The endpoints of this study were local control (LC), progression-free survival (PFS), overall survival (OS), and evaluation of toxicity induced by the treatment. 


\section{Cureus}

from initial treatment until any new local or distant lesion occurred in the brain. LC was defined as the time from initial treatment until disease progression was documented in the bed of a treated metastasis.

All survival times were computed with the Kaplan-Meier method and cumulative incidences of local recurrence were computed using competing risk analyses given the high likelihood of brain recurrences outside of the treated region and concurrent deaths.

Treatment toxicity included clinical and radiological evaluation. In our study, the definition of RN was mainly radiological. If RN was a possibility raised by the radiologist's report on follow-up MRI, regardless of the timing since SRS treatment, it was tagged as RN.

\section{Results}

A total of 141 patients with 194 lesions were reviewed. Forty percent of the patients were male and the cohort had a median age of 62 years ranging between 37 and 89 years at initial treatment. Nearly all the patients had a good performance status with a KPS $\geqslant 70$ (138 patients, 98\%) and/or an RPA $\leqslant$ II (138 patients, 98\%).

SRS as initial management for BM was performed alone in 71 patients (50\%). Twenty-one patients (23\%) had frameless SRS at the metastatic site after surgical resection and 38 patients (27\%) had SRS after whole-brain radiation therapy (WBRT). A small fraction of our cohort, 11 patients (8\%), had prior surgery and WBRT before SRS. Baseline patients characteristics and treatments are listed in Table 1 and Table 2 . 


\section{Cureus}

\begin{tabular}{|c|c|c|}
\hline & [n] & $\%$ \\
\hline Total patients & 141 & 100 \\
\hline \multicolumn{3}{|l|}{ Sex } \\
\hline Male & 57 & 40 \\
\hline Female & 84 & 60 \\
\hline \multicolumn{3}{|l|}{ RPA class } \\
\hline 1 & 24 & 17 \\
\hline II & 114 & 81 \\
\hline III & 3 & 2 \\
\hline \multicolumn{3}{|l|}{ GPA class } \\
\hline 1 & 11 & 8 \\
\hline 1.5 & 45 & 32 \\
\hline 2 & 32 & 23 \\
\hline 2.5 & 25 & 18 \\
\hline 3 & 17 & 12 \\
\hline 3.5 & 8 & 6 \\
\hline 4 & 3 & 2 \\
\hline \multicolumn{3}{|l|}{ KPS } \\
\hline 60 & 3 & 2 \\
\hline 70 & 63 & 45 \\
\hline 80 & 34 & 24 \\
\hline 90 & 35 & 25 \\
\hline 100 & 6 & 4 \\
\hline
\end{tabular}

\section{TABLE 1: Baseline Patients Demographics Characteristics}

RPA: Recursive Partitioning Analysis, GPA: Graded Prognostic Assessment, KPS: Karnofsky Performance Status

\begin{tabular}{|c|c|c|}
\hline & [n] & $\%$ \\
\hline Total patients & 141 & 100 \\
\hline \multicolumn{3}{|l|}{ Treatment plan } \\
\hline SRS alone & 71 & 50 \\
\hline WBRT + SRS & 38 & 27 \\
\hline$S x+S R S$ & 21 & 15 \\
\hline WBRT + Sx + SRS & 11 & 8 \\
\hline
\end{tabular}

\section{TABLE 2: Baseline Patients Treatment Plan}

SRS: Stereotactic Radiosurgery, WBRT: Whole Brain Radiation Therapy, Sx: Surgical Resection 


\section{Cureus}

A total of 194 lesions were treated. Ninety-nine patients (70\%) had a single brain lesion, 34 patients (24\%) had two brain lesions, and eight patients (6\%) had three brain lesions or more. The mean largest diameter of the treated lesions was $17.84 \mathrm{~mm}$, ranging between 1.00 and $72.00 \mathrm{~mm}$ with a median of $15.00 \mathrm{~mm}$. Eightyseven patients (62\%) had BM related to primary lung cancer followed by breast cancer in 19 patients (13\%) and colorectal cancer in 11 patients (8\%). Treated tumors characteristics and primary sites are summarized in Table 3.

\begin{tabular}{|c|c|c|}
\hline & [n] & $\%$ \\
\hline Total treated lesions & 194 & 100 \\
\hline \multicolumn{3}{|c|}{ Number of BM per patient (\%) } \\
\hline $1 \mathrm{BM}$ & 99 & 70 \\
\hline 2 BM & 34 & 24 \\
\hline 3 or more BM & 8 & 6 \\
\hline \multicolumn{3}{|l|}{ BM location } \\
\hline Frontal & 70 & 36 \\
\hline Parietal & 30 & 15 \\
\hline Temporal & 20 & 10 \\
\hline Cerebellar & 41 & 21 \\
\hline Occipital & 22 & 11 \\
\hline Other & 11 & 6 \\
\hline \multicolumn{3}{|l|}{ Primary cancer site } \\
\hline Lung & 87 & 62 \\
\hline Breast & 19 & 13 \\
\hline Colorectal & 11 & 8 \\
\hline Skin melanoma & 9 & 6 \\
\hline Other & 15 & 11 \\
\hline
\end{tabular}

\section{TABLE 3: Treated Tumors Characteristics and Primary Cancer Site}

BM: Brain Metastases

A single fraction of SRS was given in $94 \%$ of the radiation treatments. Fractionated radiosurgery was performed in nine patients (6\%) and was delivered in three treatment sessions. The median dose to the PTV was $15 \mathrm{~Gy}$ and ranged between 12 and $24 \mathrm{~Gy}$. The median volume of tissue receiving $10 \mathrm{~Gy}$ (V10) was $14.17 \mathrm{~cm}^{3}$ and the median volume of tissue receiving $12 \mathrm{~Gy}$ (V12) was $7.81 \mathrm{~cm}^{3}$. The median GTV and PTV were $2.91 \mathrm{~cm}^{3}$ and $5.23 \mathrm{~cm} 3$, respectively. The median Conformity Index was 1.22 and ranged between 0.81 and 2.84 and the median Paddick's Conformity Index was 0.82 and ranged between 0.53 and 1.53. Treatment parameters are summarized in Table 4. 


\section{Cureus}

\begin{tabular}{|l|lll|}
\hline & Mean & Median & Range \\
\hline Prescribed SRS dose (Gy) & 16.60 & 15.00 & $12.00-24.00$ \\
GTV $\left(\mathrm{cm}^{3}\right)$ & 6.20 & 2.91 & $0.04-126.42$ \\
PTV $\left(\mathrm{cm}^{3}\right)$ & 10.25 & 5.23 & $0.31-167,65$ \\
V10 $\left(\mathrm{cm}^{3}\right)$ & 21.25 & 14.17 & $2.70-319.87$ \\
V12 $\left(\mathrm{cm}^{3}\right)$ & 12.67 & 7.81 & $1.36-223.27$ \\
CI & 1.25 & 1.22 & $0.81-2.84$ \\
CIPaddick's & 0.82 & 0,82 & $0.53-1.53$ \\
\hline
\end{tabular}

\section{TABLE 4: Treatment Parameters}

SRS: Stereotactic Radiosurgery, GTV: Gross Tumor Volume, PTV: Planning Targeted Volume, V10: Volume of brain tissue receiving more than 10 Gy, V12: Volume of brain tissue receiving more than $12 \mathrm{~Gy}, \mathrm{Cl}$ : Conformity Index, CIPaddick's: Paddick's Conformity Index

The OS was calculated for 139 patients. Two patients were excluded for invalid time reporting. The median OS for all patients was 8.7 months (CI 95\%, 4.7-11.9). At the time of analysis, 33 patients (23\%) were still alive and the median potential follow-up time was 25.1 months (CI 95\%, 16.3-27.9). Fifty-nine patients (42\%) had either local or distant BM and the median PFS time was 5.3 months (CI 95\%, 3.8-7.0).

Local recurrence was seen as the first event in $25 \%$ of the patients in the first year and in $38 \%$ of the patients in the second year. Distant brain recurrence was seen as the first event in $18 \%$ and $21 \%$ of the patients, respectively, in the first two years. At one and two years, the cumulative incidence of RN as the first brain event was stable at $2 \%$. Death before any brain event was seen in 39 patients (27\%). The total cumulative incidence for death, RN, or any brain recurrence was $74 \%$ and $91 \%$ at one and two years, respectively (Figure 2).

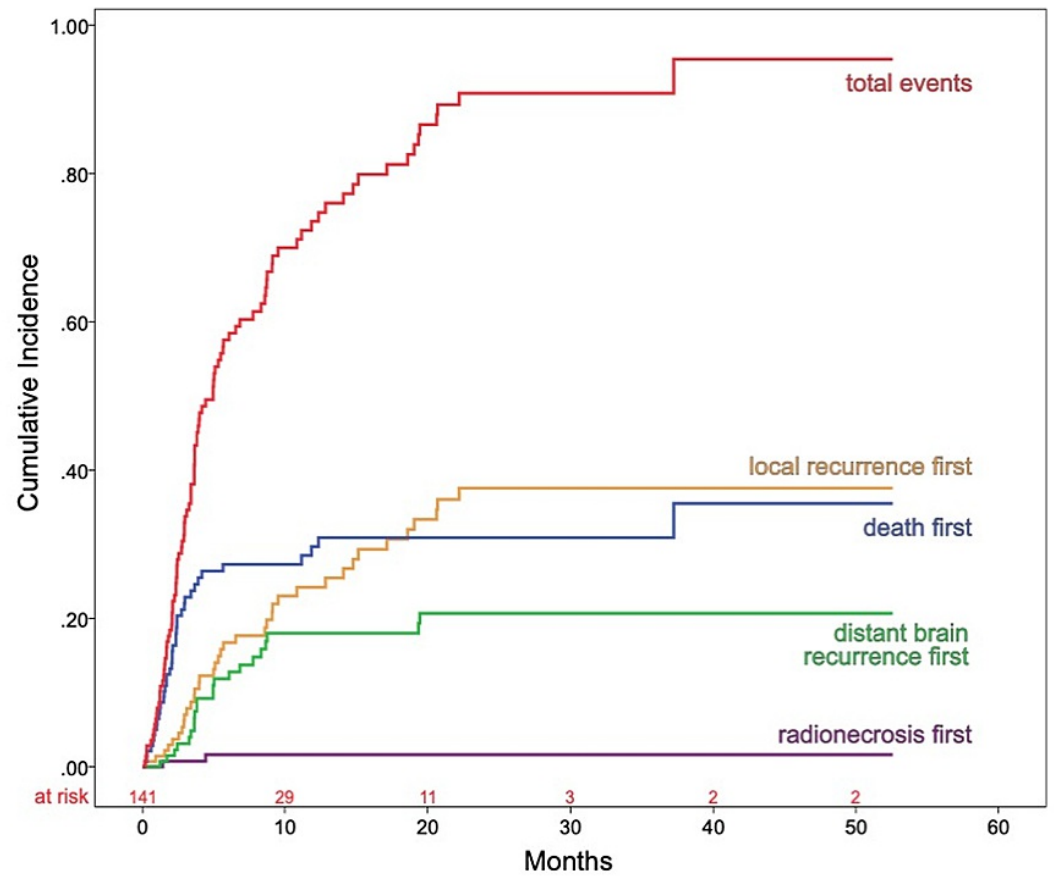

FIGURE 2: Cumulative Incidence of Radionecrosis, Local Recurrence, Distant Brain Recurrence, and Death as First Event

In our study, only two patients had RN as the most likely brain event; this diagnosis was made on follow-up 
MRI at 1.4 months and 4.4 months after initial treatment, respectively. Both patients were women with good performance scores (RPA II, KPS $\geqslant 70$, GPA between 1.5 and 2). Both patients had only SRS for their BM with no prior history of WBRT or surgical resection. Both patients were treated with a single fraction SRS of 15 Gy or $18 \mathrm{~Gy}$, respectively. A multivariate analysis was performed to assess for predictors of RN, including sex, RPA, GPA, KPS, prior WBRT or SRS, primary tumor site, number of brain metastases, the use of unfractionated versus fractionated SRS, and the dose prescribed to PTV. Although, unsurprisingly, with only two events, none were found to be statistically significant.

\section{Discussion}

The efficacy of LINAC-based SRS for extra-cranial tumors has been well-documented in the literature for the lungs, liver, and spine [14]. Nowadays, SRS is increasing in popularity for BM treatment and multiple noninvasive frameless LINAC delivery units exist, but the data on their therapeutic impact are still to be gathered.

This retrospective study reports data on 141 patients treated with frameless LINAC-based SRS for intracranial metastasis from various primary sites. Our objective was to document SRS BM treatment outcome and toxicity in our institution.

At the time of analysis, 33 patients were still alive with a median follow-up time of 25.1 months. Our cohort had an overall median OS of 8.7 months, which is comparable to the Hauswald et al. [15] and Breneman et al. [6] studies that reported a median OS of 9 and 8.1 months, respectively. Minniti et al., however, reported a longer OS of 14.1 months in a 206 patient-based study [2]. The differences between our study and Minniti et al. could be explained by a difference in the patient selection process. Minniti et al. based their study on patients with BM size $<3.5 \mathrm{~cm}$, and they excluded all patients previously treated with SRS, WBRT, or surgery. The inclusion criteria in our study were wider and included patients with larger BM, up to $4 \mathrm{~cm}$, and possibly more aggressive cancers since we included patients who had prior surgical resection and/or WBRT. Furthermore, three patients (2\%) had a documented KPS score of 60 , but they were still included in our study, as they were found to benefit from frameless SRS on clinical evaluation. The median PFS in our study was 5.3 months, which is also comparable to data reported in the literature. A comparison and overview of the prior literature on frameless LINAC-based SRS is reported in Table 5. 


\begin{tabular}{|c|c|c|c|c|c|c|}
\hline & $\begin{array}{l}\text { Kamath et al. } \\
\text { [16] }\end{array}$ & $\begin{array}{l}\text { Breneman et } \\
\text { al. [6] }\end{array}$ & Nath et al. [5] & Minniti et al. [2] & $\begin{array}{l}\text { Hauswald et al. } \\
\text { [15] }\end{array}$ & Present study \\
\hline [n] patients & 64 & 53 & 65 & 206 & 84 & 141 \\
\hline [n] BM treated & NR & 158 & 204 & 310 & 140 & 194 \\
\hline SRS technique & $\begin{array}{l}\text { Frameless } \\
\text { LINAC-based } \\
\text { SRS }\end{array}$ & $\begin{array}{l}\text { Frameless } \\
\text { LINAC-based } \\
\text { SRS }\end{array}$ & $\begin{array}{l}\text { Frameless } \\
\text { LINAC-based } \\
\text { SRS }\end{array}$ & $\begin{array}{l}\text { Frameless } \\
\text { LINAC-based } \\
\text { SRS }\end{array}$ & $\begin{array}{l}\text { Frameless } \\
\text { LINAC-based } \\
\text { SRS }\end{array}$ & $\begin{array}{l}\text { Frameless } \\
\text { LINAC-based } \\
\text { SRS }\end{array}$ \\
\hline Prescribed dose & $\begin{array}{l}17.5 \mathrm{~Gy} \\
\text { (median) }\end{array}$ & 18 Gy (median) & 18 Gy (median) & 18 Gy (mean) & 20 Gy (median) & 15 Gy (median) \\
\hline \multirow{3}{*}{$\begin{array}{l}\text { [n] BM per patient } \\
\text { (range) }\end{array}$} & \multirow{3}{*}{ Median: $2(1-4)$} & \multirow{3}{*}{$\begin{array}{l}\text { Median: } 2 \text { (1- } \\
\text { 15) }\end{array}$} & \multirow{3}{*}{ Median: 2 (1-13) } & $1: 126 \mathrm{pts}$ & $1: 49 \mathrm{pts}$ & $1: 99 \mathrm{pts}$ \\
\hline & & & & $2: 56$ pts & 2-3: 31 pts & 2-3: 40 pts \\
\hline & & & & $3: 24$ pts & $\geq 4: 4$ pts & $\geq 4: 2$ pts \\
\hline OS (median) & $8.7 \mathrm{mo}$ & $\begin{array}{l}\text { RPA I: } 18 \text { mo } \\
\text { RPA II-III: } 8.1 \\
\text { mo }\end{array}$ & $40 \%$ at 1 year & $14.1 \mathrm{mo}$ & $9 \mathrm{mo}$ & $8.7 \mathrm{mo}$ \\
\hline PFS (median) & $8.1 \mathrm{mo}$ & NR & $\begin{array}{l}46 \% \text { at } 1 \text { year of } \\
\text { regional control }\end{array}$ & $10 \mathrm{mo}$ & $5.3 \mathrm{mo}$ & $5.3 \mathrm{mo}$ \\
\hline \multirow[t]{2}{*}{ Median follow-up time } & \multirow[t]{2}{*}{$8.2 \mathrm{mo}$ (overall) } & \multirow[t]{2}{*}{ NR } & $\begin{array}{l}18.1 \mathrm{mo} \text { (survived } \\
\text { patient) }\end{array}$ & \multirow[t]{2}{*}{9.4 mo (overall) } & \multirow[t]{2}{*}{7 mo (overall) } & \multirow{2}{*}{$\begin{array}{l}25 \text { mo (survivec } \\
\text { patient) }\end{array}$} \\
\hline & & & $6.2 \mathrm{mo}$ (overall) & & & \\
\hline $\begin{array}{l}\text { [n] patients alive at } \\
\text { time of the analysis (\%) }\end{array}$ & NR & 29 (55\%) & $16(25 \%)$ & $91(44 \%)$ & $11(19 \%)$ & $33(23 \%)$ \\
\hline [n] radionecrosis $(\%)$ & none & $2(3.8 \%)$ & $1(1.5 \%)$ & $12(5.8 \%)$ & $1(1.2 \%)$ & $2(1.4 \%)$ \\
\hline
\end{tabular}

\section{TABLE 5: Frameless LINAC-Based SRS: Overview of Prior Studies}

NR: Not Reported, Pts: Patients, BM: Brain Metastases, LINAC: Linear Particle Accelerator, SRS: Stereotactic Radiosurgery, RPA: Recursive Partitioning Analysis

The median OS in our study is also similar to the frame-based SRS technique in the literature. A large, prospective, SRS frame-based study by Serizawa et al. [17] reported a median OS at 8.3 months for RPA II class patients $(\mathrm{n}=2150)$. However, to our knowledge, no prospective study has yet compared these two modalities.

Kimmel et al. [18] published a meta-analysis on brain metastasis management and, according to their data, SRS, with or without WBRT, should be the initial treatment for BM. Based on the present study and frameless LINAC-based SRS literature, it is not only possible to use that strategy as initial treatment for BM, but it is also an option associated with acceptable PFS and OS time. When comparing traditional frame-based SRS literature with frameless SRS, non-invasive frameless SRS offers better comfort levels and decreases anxiety for the patient [6]. Frameless SRS also allows for an easier way to deliver fractionated radiotherapy, which could be useful when the brain metastases are large, oddly shaped, or near critical structures such as cranial nerves, deep gray matter, or the brainstem [6,12,19-21]. Furthermore, the use of SRS without WBRT was associated with fewer side effects like hair loss, fatigue, and cognitive dysfunction [22].

As for the adverse events documented in our cohort, two patients (1.4\%) developed radiological findings of RN on follow-up MRI. Analysis of the demographic and prognostic parameters for RN was not found to be statistically significant. However, this is expected given only two cases of RN were reported. This is comparable to the rate of RN previously documented in prior studies, stating a range of RN between $1.2 \%$ and $5.8 \%[2,5-6,15]$. However, imaging alone remains notoriously inaccurate in diagnosing $\mathrm{RN}$, the gold standard remains a brain biopsy, which was not performed in our patients. Moreover, imaging features of RN may overlap with findings of cancer recurrence or pseudo-progression, therefore overestimating the incidence of RN [23-24]. Although there is a low incidence of RN in our study, a case report published by Hyde C et al. [25] states that fractionated radiotherapy may provide a reduction in the incidence of toxicity, including RN, and it is a safe and well-tolerated method for the treatment of multiple brain metastasis [26]. 
Our study had some limitations. First, the main limitation is related to its retrospective nature, making follow-up data inherently suboptimal. Second, our patient cohort was heterogeneous, with various prior treatments and primary neoplasms, which limited our analysis. Third, when we first initiated this technique in our center, we only selected patients with good performance status (RPA, GPA, KPS). However, with new data on SRS use for BM management being published, we loosened our inclusion criteria, therefore enlarging our population to more severe diseases.

Overall, the first results of our study seem promising for frameless LINAC-based SRS, and to our knowledge, this study has one of the longest follow-up periods in a retrospective study in the literature.

\section{Conclusions}

The treatment of BM with LINAC-based frameless SRS in our institution had an OS and PFS comparable with the literature for frameless SRS and for conventional frame-based SRS while being less invasive and more comfortable for the patient. In our study, frameless SRS with LINAC technology seems to be safe for BM treatment with minimal rates of radiation necrosis.

\section{Additional Information \\ Disclosures}

Human subjects: Consent was obtained or waived by all participants in this study. Animal subjects: All authors have confirmed that this study did not involve animal subjects or tissue. Conflicts of interest: In compliance with the ICMJE uniform disclosure form, all authors declare the following: Payment/services info: All authors have declared that no financial support was received from any organization for the submitted work. Financial relationships: All authors have declared that they have no financial relationships at present or within the previous three years with any organizations that might have an interest in the submitted work. Other relationships: All authors have declared that there are no other relationships or activities that could appear to have influenced the submitted work.

\section{References}

1. Kaal ECA, Niël CGJH, Vecht CJ: Therapeutic management of brain metastasis . Lancet Neurol. 2005, 4:28998. 10.1016/S1474-4422(05)70072-7

2. Minniti G, Clarke E, Lanzetta G, et al.: Stereotactic radiosurgery for brain metastases: analysis of outcome and risk of brain radionecrosis. Radiat Oncol. 2011, 6:48. 10.1186/1748-717X-6-48

3. Mazeron JJ, Valéry CA, Boisserie G, Cornu P: History of radiosurgery [Article in French] . Cancer Radiother. 2012, 16 Suppl:S2-4. 10.1016/j.canrad.2011.09.004

4. Leksell L: The stereotaxic method and radiosurgery of the brain . Acta Chir Scand. 1951, 102:316-9.

5. Nath SK, Lawson JD, Wang JZ, et al.: Optically-guided frameless linac-based radiosurgery for brain metastases: clinical experience. J Neurooncol. 2010, 97:67-72. 10.1007/s11060-009-9989-y

6. Breneman JC, Steinmetz R, Smith A, Lamba M, Warnick RE: Frameless image-guided intracranial stereotactic radiosurgery: clinical outcomes for brain metastases. Int J Radiat Oncol Biol Phys. 2009, 74:7026. 10.1016/j.ijrobp.2008.11.015

7. Ma Y, Li M, Yin Y, Kong L, Sun X, Lin X, Yu J: Hypofractionated stereotactic radiotherapy for brain metastases: a dosimetric and treatment efficiency comparison between volumetric modulated arc therapy and intensity modulated radiotherapy. Technol Cancer Res Treat. 2010, 9:499-507. $10.1177 / 153303461000900508$

8. Gaspar L, Scott C, Rotman M, et al.: Recursive partitioning analysis (RPA) of prognostic factors in three Radiation Therapy Oncology Group (RTOG) brain metastases trials. Int J Radiat Oncol Biol Phys. 1997, 37:745-51. 10.1016/s0360-3016(96)00619-0

9. Sperduto PW, Berkey B, Gaspar LE, Mehta M, Curran W: A new prognostic index and comparison to three other indices for patients with brain metastases: an analysis of 1,960 patients in the RTOG database. Int J Radiat Oncol Biol Phys. 2008, 70:510-4. 10.1016/j.ijrobp.2007.06.074

10. Shaw E, Scott C, Souhami L, Dinapoli R, Kline R, Loeffler J, Farnan N: Single dose radiosurgical treatment of recurrent previously irradiated primary brain tumors and brain metastases: final report of RTOG protocol 90-05. Int J Radiat Oncol Biol Phys. 2000, 47:291-8. 10.1016/s0360-3016(99)00507-6

11. Flickinger JC, Kondziolka D, Lunsford LD, Kassam A, Phuong LK, Liscak R, Pollock B: Development of a model to predict permanent symptomatic postradiosurgery injury for arteriovenous malformation patients. Int J Radiat Oncol Biol Phys. 2000, 46:1143-8. 10.1016/s0360-3016(99)00513-1

12. Stafford SL, Pollock BE, Leavitt JA, et al.: A study on the radiation tolerance of the optic nerves and chiasm after stereotactic radiosurgery. Int J Radiat Oncol Biol Phys. 2003, 55:1177-81. 10.1016/s03603016(02)04380-8

13. Blonigen BJ, Steinmetz RD, Levin L, Lamba MA, Warnick RE, Breneman JC: Irradiated volume as a predictor of brain radionecrosis after linear accelerator stereotactic radiosurgery. Int J Radiat Oncol Biol Phys. 2010, 77:996-1001. 10.1016/i.ijrobp.2009.06.006

14. Ma L, Wang L, Tseng CL, Sahgal A: Emerging technologies in stereotactic body radiotherapy . Chin Clin Oncol. 2017, 6:S12. 10.21037/cco.2017.06.19

15. Hauswald H, Stenke A, Debus J, Combs SE: Linear accelerator-based stereotactic radiosurgery in 140 brain metastases from malignant melanoma. BMC Cancer. 2015, 15:537. 10.1186/s12885-015-1517-1

16. Kamath R, Ryken TC, Meeks SL, Pennington EC, Ritchie J, Buatti JM: Initial clinical experience with frameless radiosurgery for patients with intracranial metastases. Int J Radiat Oncol Biol Phys. 2005, 


\section{Cureus}

61:1467-72. 10.1016/j.ijrobp.2004.08.021

17. Serizawa T, Higuchi Y, Nagano O: Stereotactic radiosurgery for brain metastases . Neurosurg Clin N Am. 2013, 24:597-603. 10.1016/j.nec.2013.05.007

18. Kimmell KT, LaSota E, Weil RJ, Marko NF: Comparative effectiveness analysis of treatment options for single brain metastasis. World Neurosurg. 2015, 84:1316-32. 10.1016/j.wneu.2015.06.021

19. Minniti G, Scaringi C, Paolini S, et al.: Single-fraction versus multifraction ( $3 \times 9 \mathrm{~Gy})$ stereotactic radiosurgery for large $(>2 \mathrm{~cm}$ ) brain metastases: a comparative analysis of local control and risk of radiationinduced brain necrosis. Int J Radiat Oncol Biol Phys. 2016, 95:1142-8. 10.1016/j.ijrobp.2016.03.013

20. Higuchi Y, Serizawa T, Nagano O, et al.: Three-staged stereotactic radiotherapy without whole brain irradiation for large metastatic brain tumors. Int J Radiat Oncol Biol Phys. 2009, 74:1543-8. 10.1016/j.ijrobp.2008.10.035

21. Sakamoto T, Shirato H, Sato N, et al.: Audiological assessment before and after fractionated stereotactic irradiation for vestibular schwannoma. Radiother Oncol. 1998, 49:185-90. 10.1016/s0167-8140(98)00090-5

22. Zindler JD, Bruynzeel AME, Eekers DBP, Hurkmans CW, Swinnen A, Lambin P: Whole brain radiotherapy versus stereotactic radiosurgery for 4-10 brain metastases: a phase III randomised multicentre trial. BMC Cancer. 2017, 17:500. 10.1186/s12885-017-3494-z

23. Rahmathulla G, Marko NF, Weil RJ: Cerebral radiation necrosis: a review of the pathobiology, diagnosis and management considerations. J Clin Neurosci. 2013, 20:485-502. 10.1016/j.jocn.2012.09.011

24. Rogers LR, Gutierrez J, Scarpace L, et al.: Morphologic magnetic resonance imaging features of therapyinduced cerebral necrosis. J Neurooncol. 2011, 101:25-32. 10.1007/s11060-010-0222-9

25. Hyde C, Kinser S, Croft C, et al.: Fractionated radiosurgery alone for thirty-seven brain metastases: not everything that can be counted counts. Cureus. 2017, 9:e1985. 10.7759/cureus.1985

26. Fahrig A, Ganslandt O, Lambrecht U, Grabenbauer G, Kleinert G, Sauer R, Hamm K: Hypofractionated stereotactic radiotherapy for brain metastases. Results from three different dose concepts. Strahlenther Onkol. 2007, 183:625-30. 10.1007/s00066-007-1714-1 